\title{
Head-mounted cameras and stimulated recall in qualitative sport research
}

\author{
Susan Houge Mackenzie ${ }^{\mathrm{a}}$ and John H. Kerr ${ }^{\mathrm{b} *}$ \\ ${ }^{a}$ Department of Movement Sciences, College of Education, University of Idaho, Moscow, \\ Idaho 83844-3080, USA; ${ }^{b}$ School of Kinesiology, University of British Columbia, 210-6081 \\ University Blvd, Vancouver, BC, Canada, V6P $1 Z 1$
}

\begin{abstract}
There are a number of innovative procedures available for use in qualitative research, including observation, note-taking and verbal protocol techniques. This paper highlights the potential usefulness of stimulated recall as an innovative technique for use in qualitative research in sport and possibly exercise. Specifically, it focuses on video footage obtained from head-mounted cameras for use in stimulated recall during post-event interviews. Examples of research studies carried out in simulation training with fire and emergency personnel and with leisure participants in a whitewater adventure setting, are used to illustrate how stimulated recall can be utilised effectively in practice. Participants in a river-surfing course completed daily qualitative semi-structured interviews, facilitated by footage from head-mounted video cameras. The cameras were worn throughout the course while participants were in the water. The use of the headmounted equipment and video-footage as stimulated recall in the study and preliminary findings about the procedure are described. Finally, a number of advantages and disadvantages of head-mounted camera and stimulated recall procedures in general are discussed.
\end{abstract}

keywords: stimulated recall; head-mounted cameras; interviews; adventure settings; qualitative research

Recently, Neil et al. (2009) outlined how the use of qualitative research methods has advanced the understanding of performers' experiences of anxiety and stress in competition. In the review, the authors focused on a selection of the numerous techniques available to collect, analyse and present qualitative data. Many of the points they made go beyond anxiety and stress research and are relevant to research on other aspects of sport performance and/or experience. For example, the authors gave their support to alternative multiple-method approaches to data collection and mentioned the use of observation, note taking and verbal protocol techniques as examples of innovative procedures. One example of an innovative approach to collecting qualitative data not included in the review (Neil et al. 2009) is the use of stimulated recall with participants in post-event interviews. This is the subject of this manuscript, which examines the use of stimulated recall in qualitative research, with the aim of drawing readers' attention to its potential for enhancing the collection of data obtained in post-event interviews in other sport and exercise contexts. 
A study undertaken to enhance fire and emergency personnel's emergency incident command and control skills (McLennan et al. 2005), along with one carried out in an adventure setting (Houge 2010) are used to illustrate how stimulated recall can be utilised effectively in practice.

\section{Stimulated recall interviews}

There are a variety of interview techniques available to the qualitative researcher (e.g. Sparkes and Smith 2009). These include interactive, structured, semistructured, life history, focus group, feminist, self-confrontational and stimulated recall interviews, all of which have been used in sport and exercise research. There are advantages and disadvantages associated with each type of interview and researchers must choose between them for the one most suitable for obtaining the relevant information from participants in their particular study. This may mean moving away from the standardised, highly structured format associated with the traditional approach to qualitative interviews in sport and exercise psychology. Smith (2010) provided a useful debate about what is meant by an interview. In it, he covered the issues involved in choosing between traditional approaches to interviews and what he considered to be the more innovative approaches to interviews currently being used in narrative research. It is against this background of a broadening approach to qualitative interviews that the present authors wish to discuss the use of stimulated recall research in sport and exercise psychology.

A stimulated recall interview is an introspective research procedure which uses audio recordings, video footage, photographs or other aids to assist research participants to recall their experience of an event during post-event interviews. In comparison with free recall, the use of video-assisted recall has proved superior in facilitating recall during post-event interviews. Video-assisted recall was found to facilitate significantly greater immersion and specificity of recall regarding key thoughts and feelings, as well as providing a powerful stimulus to recall and verbalise important performance-related mental events (Omodei et al. 1998, McLennan et al. 2005). As Dempsey (2008, p. 350) pointed out:

Motivations and rationales that informants describe retrospectively may not conform to those that they actually held in the moment of the experience. The technique of SRI [stimulated recall interviews] brings informants a step closer to the moments in which they actually produce action. It gives them the chance to listen or view themselves in action, jog memories, and give answers of 'I did' instead of 'I might have'.

Recent examples of video-assisted stimulated recall research include using the procedure: to investigate how people coordinate their interactions in different social situations, such as jazz jam sessions (Dempsey 2008); to identify and explore gendered constructions of power during discourse about sexual harassment (Dougherty 2006) and to examine the temporal dynamics of acrobatic activity and how the concept of 'meaningful time' is constructed and used by elite athletes during acrobatic performance (Hauw and Durand 2008).

In Hauw and Durand (2008) study, recordings of the beginning, take-off and landing of an acrobatic movement were made with a wide-angled digital camera and discussed in subsequent interviews. In other studies using stimulated recall, head-mounted video cameras have been used (e.g. Brown et al. 2008, Houge 
2010). In these studies, video footage is obtained by light-weight head-mounted video cameras attached to headbands (like a headlamp using for camping), or helmets where the participants wear helmets as part of the activity. At the same time, the camera equipment also records audio sound from a microphone. The scene or the action is recorded from a point on the wearer's head or head-wear and provides participants with a very personal view of the event as they took part in it. Stimulated recall from head-mounted cameras is thought to be advantageous when compared to recall from cameras placed in other locations relative to participants:

When an individual watches a conventional video replay of him or herself engaged in a task taken from an external perspective, the result is frequently self-consciousness, evaluation anxiety, and defensiveness leading to biased selectivity in what is recalled. However, when the same individual watches a replay of video footage taken from his or her own visual perspective (using a head-mounted camera) while a task was undertaken there is minimal self consciousness, there is a high level of psychological re-immersion in the original task activity, and the individual is usually able to recall in great detail the underlying mental events that generated the task activities. (McLennan et al. 2005, p. 11)

In order to clearly understand stimulated recall research, it is worth taking a more detailed look at the research work carried out by McLennan, Omodei and their colleagues. Typical of their highly practice-oriented research work is a study aimed at using stimulated recall for enhancing fire and emergency service personnel's emergency incident command and control skills, reported by McLennan et al. (2005). The participants were male candidates for promotion from Station Officer to Senior Station Officer with experience ranging between 10 and 20 years in the service and between 4 and 12 years experience as Station Officers. The participants spent five days undertaking a range of role playing simulation exercises in which each took on the role of incident controller.

During the simulation exercises each 'incident controller' first listened to the initial radio turnout message, received a message from the first appliance on the scene and assumed control of the incident. Scripted role players provided reports and carried out the incident controllers' instructions. After the incident had developed for about 15-20 min, an instructor assumed the role of a 'superior officer' who had arrived on the scene to take charge of the incident. The incident controller was then required to brief the superior officer on the situation. Once this briefing had taken place, the exercise ended. On the first three days of simulation exercises incident controllers wore helmet-mounted cameras and, on the last two days, a conventional hand-held camera was used to film events (McLennan et al. 2005).

Based on the researchers' previous experience in similar training exercises, a procedure was developed for the use of head-mounted video footage. Similar verbal instructions were given to each participant in the recall sessions and their recollections and responses were recorded. These verbal instructions provide good examples of the type of instructions and questions that researchers could use prior to and during stimulated recall interviews. For example, just prior to replaying the video in the recall sessions:

We are going to watch a replay of footage of the exercise taken from the helmet camera. As you watch, I want you to take yourself back to being in the role of the IC [incident controller]. I want you to recall as much as you can of what was going on in 
your mind when you were managing the incident. I want you to speak these recollections out loud - just begin talking and I will pause the tape so you have plenty of time to recall as much as you can. (McLennan et al. 2005, p. 13)

After the helmet camera tape was rewound and the image paused:

Now, as you watch this picture of the start of the exercise take yourself back - what do you recall thinking just as the exercise was about to begin? (McLennan et al. 2005, p. 13)

At the end of the replay, the participant was asked:

Now that you have watched the incident run through, if you could magically turn the clock back and do it again, what, if anything, might you do differently and why? (McLennan et al. 2005, p. 13)

The person conducting the interview session could pause or rewind the tape if required and occasionally use non-directive probes to encourage the participant to recall as much as possible. If necessary, they could also remind the participant to engage in recall rather than self-criticism. In this case, a copy of the video tape and the participant's comments during the recall session were provided to each participant for discussion among instructors and fellow fire and rescue personnel.

As it turned out, all the participants were later passed as eligible for promotion to Senior Station Officer, but more importantly with regard to stimulated recall, their responses to an evaluation questionnaire completed at the end of the training, indicated that participants were uniformly positive about the benefits of videoassisted recall as contributing significantly to enhancing their incident control skills.

McLennan et al.'s (2005) research work was strongly oriented towards practical outcomes for fire and emergency personnel, who are required to make crucial decisions in dangerous situations as an occupational requirement. However, there are other individuals who willingly seek out danger and put themselves at risk in recreational adventure settings. Qualitative research techniques in general, and stimulated recall interviews in particular, can be a very valuable means of studying participants' experience of adventure activities. The recorded statements obtained during stimulated recall interviews can, for example, provide important psychological data for understanding participants' motivation for participation and emotional experience during the activity. The next section examines the use of qualitative research and stimulated recall in adventure settings, focusing on an example of psychological research in a whitewater adventure activity.

\section{Stimulated recall in adventure settings}

There is an element of risk of injury or death in adventure activities (e.g. hang-gliding, skydiving and whitewater canoeing), which means that safety helmets are worn as a requirement of participation in those activities. In skydiving, for example, it has become common practice to have one skydiver known as the 'camera' jump out of the aircraft with the other skydivers and film their descent with a helmetmounted camera. This footage is then viewed back on the ground by the other skydivers as an aid to improving aspects of their skydiving performance, especially where complicated groups or team manoeuvres are involved. Taking this procedure 
one stage further, it is possible to fit individual skydivers with helmet-mounted cameras and obtain video film showing a personal perspective of their descent. Where resources allow it, several individuals can wear head-mounted cameras during the same activity. In skydiving and other adventure sports, the use of lightweight head-mounted cameras on participants' helmets causes little or no interference with performing the activity. Thus, adventure sports easily lend themselves to this largely unobtrusive method of data collection, which can be used as stimulated recall in post-event interviews.

\section{An example from whitewater adventure activity}

The naturalistic environment of whitewater activity was the adventure setting for a multiple-method longitudinal psychological study which utilised semi-structured interviews and stimulated recall (Houge 2010). An advanced riversurfing course, incorporating rapids of different degrees of difficulty and other challenging elements, was used to explore optimal and non-optimal experiences among participants. The theoretical base of the research was provided by flow theory (Csikszentmihalyi 1975) and reversal theory (Apter 1982, 2001). These are two general psychological models which are relatively well known in sport and exercise psychology (e.g. Kerr 1997, 2001). Flow theory (Csikszentmihalyi 1975, Jackson 1996) attempts to explain why people take part in some activities, with no extrinsic rewards and how they feel while doing so. It is particularly concerned with the exceptionally pleasant states known as optimal or 'flow' experiences which occur for some individuals while engaged in certain activities. Reversal theory (Apter 1982, 2001) is a theory of motivation, emotion and personality based on a structure of opposing pairs of motivational states and the reversals between these states (e.g. between the telic [serious] and paratelic [playful] pair of states). Attempts were made in the research study to combine aspects of both approaches.

Both qualitative and quantitative methods were used in the research. A concurrent nested design was employed in which the primary (qualitative, inductive and deductive) data source was given greater weighting and consideration in analysis than the secondary (quantitative) data (Creswell et al. 2003). It is the qualitative aspect of the study which is at focus here. For the qualitative data collection, five of the participants on the course (purposefully selected to represent a cross-section of the range of the group's outdoor and whitewater experience) wore stimulated recall equipment during their riversurfing activities. The stimulated recall equipment consisted of a small, water-proofed digital video camera mounted on the front of participants' safety helmets (see Figure 1). 'Helmet HERO Wide' cameras (Model Number: GHHW5170) manufactured by GoPro were used in the study. At the end of each course section, the footage from the cameras was downloaded into a laptop computer and compiled for replay use with each of the five individuals.

Charmaz (2001, p. 682) advocated the use of multiple sequential interviews as a 'stronger basis of creating a nuanced understanding of processes of interest'. Consequently, participants were interviewed after exiting the river on each day of the three-day course in a quiet location in which the video replay equipment (lap-top computer) had been set up. The first two semi-structured interviews for each participant were conducted in a large van located at the base campsite, near the riverbank and the final set of interviews was conducted off site. Interviews lasted between 25 


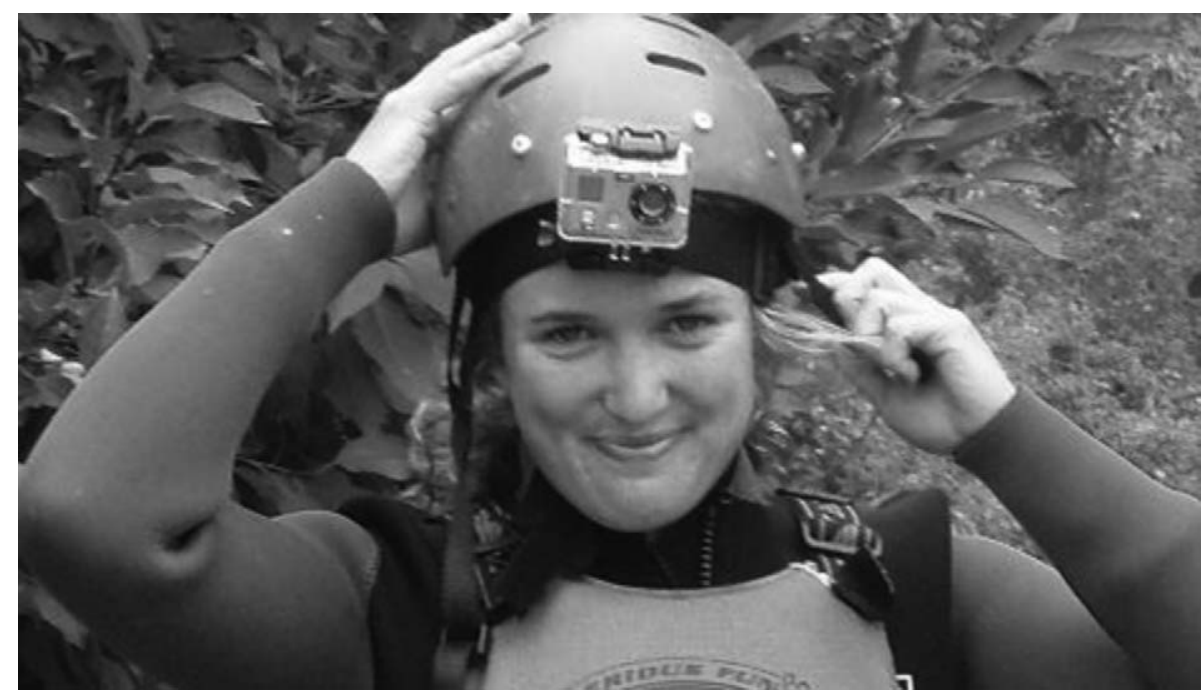

Figure 1. Participant wearing head-mounted digital video camera (used with permission).

and $55 \mathrm{~min}$ each and participants were rotated on the interview schedule to minimise order effects.

The structure of the interviews was strongly influenced by the debriefing interviews conducted by McLennan et al. (2005) and was carried out in a similar way. During each interview, participants viewed river footage from their head-mounted video camera and were asked to provide a real-time commentary. Following pilot interviews prior to data collection and debriefing, a standardised set of questions and topics were created (Patton 2002). However, the sequencing of topics and the use of probing questions (e.g. What were your thoughts and feelings during this experience?, What motivated you before this experience?, Could you describe anything that influenced your experience (either positively or negatively)?) was flexible, depending on the participant's experiences and any themes which emerged during the interview (Gratton and Jones 2004). The interviewer was an experienced riversurfing guide and therefore able to ask participants questions regarding the constructs of interest (e.g. possible experience of flow states and their feelings and emotions) at key points during the viewing of the whitewater riversurfing activity. Where necessary, to allow participants to make longer statements, or to review the action a second time, the videotape was paused or rewound so that the stimulated recall interview could be a 'stop-and-start highly interactive process' (Dempsey 2010, p. 355).

All interviews were digitally recorded verbatim and interview statements were later analysed following well-established procedures for analysing inductive and deductive data (e.g. Creswell et al. 2003). The interviewer/researcher immersed herself in the interview data, familiarising herself with the audio recordings and verbatim data transcripts while transcribing the interviews. After transcription, each interview was examined for key themes, which were then marked and, if applicable, notes relating them to theoretical concepts from flow or reversal theory made alongside. These key raw data quotes and themes were then grouped into related themes and any unique themes noted. Procedures for member checking, interview coding 
and consistency, establishing trustworthiness and conducting an audit trail were also employed.

The psychological results from the study are being published elsewhere, but some brief examples to illustrate how stimulated recall worked and the type of information, relating to flow states and motivational state reversals, obtained are included here.

For example, a straightforward illustration of how the stimulated recall worked during the interviews was provided by 'Dan' (all participants names are pseudonyms). As he watched the video-tape, he made a general comment about the type of manoeuvres he had attempted when he encountered the river rapids:

Quite often when we come the rapids I was like right, I'm gonna try something on it, or do something if it's possible - but I kinda didn't really know what to look for ... So, it was like trying to find the stuff to hit and try and do something like a barrel roll or jump off it - or try and get a bit of air out of it.

Shortly after, while watching the action at one particular set of rapids, he made a specific comment about not remembering which manoeuvre he had attempted. However, viewing the film confirmed an unsuccessful attempt at a barrel roll:

I think I tried to do a barrel roll - maybe not (laughs). Maybe I just went underwater - I can't remember ... [then on film he says: 'the barrel roll didn't work'] - Yeah, there you go! (laughing). (Houge 2010, additional participant statements)

The stimulus provided by the video reminded him of what had occurred and this along with his comment then provided an opening for the interviewer to ask about what he was thinking and feeling at that time.

A second example illustrates the type of information revealed from the stimulated recall interviews about participants' experience of flow states and how they could be associated with reversals in motivational states. This example concerned 'Mitch' and an intense emotional change which characterised his experience at Citroen rapid. As he stood at the top of the largest rapid of the course, Mitch reported being nervous, a state of mind characteristic of the telic (serious) state:

I wasn't nervous until I was standing right out there on the rock ... I stood there forever. And the more you stand there, the more nervous you get.

Mitch then reported singing rock music to increase his arousal level before entering the water, losing his nervousness and experiencing a highly enjoyable flow state in which he was totally involved in the kinaesthetic sensation of the situation:

I started singing Judas Priest [heavy metal music] and getting pumped up ... Then as soon as you hit the water, all your worries just float away. And by the end you're just really, really happy ... I was just enjoying myself. I wasn't kicking at all, just getting slammed around; felt like you were in a washing machine ... It was a lot of fun ... I was just focused on myself and the one foot area of water around me ... It was over just like that ... I came out with this huge smile on my face ... completely exhausted. It almost felt like you'd just been beaten up ... takes your breath away ... [I] ran back to go do it again ... because it was a great time. (Houge 2010, p. 175) 
According to reversal theory, Mitch underwent a telic (serious) to a paratelic (playful) motivational state reversal prompted by the whitewater activity. Another example involved 'Jenna' at Old Dog Leg rapid where, like Mitch at Citroen rapid, she experienced a 'big high' and her 'highlight' of day two. As she watched the footage taken while walking up to the rapid she stated that:

I was not keen on doing it at all until we stopped ... I was looking down on it thinking it doesn't look that bad ... like, OK it's my last challenge of the day, I want to do it ... for me ... I'd already psyched up to do it ... But once I knew there was a plank [to jump off], the water was not the worry, [jumping off] the plank was the worry.

It was big and exciting, but it also looked controllable. It didn't look like a situation where I was going to have to kick ... I was just worried about falling prematurely ... Everyone else had jumped and there were no rocks, so it didn't look like I could hit anything. It was more, how long am I going to be down for? What if I get tangled in the board?

I changed [the way I felt] halfway down ... I was stoked! [I] definitely [felt] pleasant ... My board got upside down ... and I didn't care ... I was really excited ... I could have stayed in there for another half an hour ... I was happy that I had done it ... It was a big thing in that, one, I don't do heights and, two, ... it seemed like Old Dog Leg [rapid] was a step up ... I wanted to do it which was this massive contradiction from this morning. (Houge 2010, p. 232)

The participant statements above are representative of many other similar quotes which emanated from the study. It should immediately be apparent to readers how the descriptions capture the intense feelings and emotions and the sometimes rapid changes in them associated with meeting the challenge of the whitewater adventure activities. Observations made during, and anecdotal feedback after the interviews suggested that: (a) visual and auditory cues from the video footage did appear to facilitate participants' recall of events and how they experienced them and (b) participants familiar with the environment or activity, recognised environmental cues in video footage better than those participants experiencing new environments or activities. Therefore, this methodology may be more effective with experienced, or possibly intermediate participants.

Houge's (2010) novel approach to qualitative data collection in whitewater activities using stimulated recall equipment has set a valuable precedent for future qualitative research methodologies in adventure sports. However, while there are a number of advantages associated with the use of head-mounted cameras for stimulated recall in research, there are also some disadvantages.

\section{Advantages and disadvantages of using stimulated recall}

Replaying visual and auditory data from participants' recent experiences can facilitate the interview process without resorting to other data collection procedures which might be intrusive or disruptive to participants' internal thought processes. The procedure can successfully elicit participants' accounts of their dynamic experience and maintain the benefits of a naturalistic context. It is particularly well suited to investigations of highly mobile, fast, risky, spatially constrictive or skilled practices (Brown et al. 2008) that are otherwise difficult for researchers to gain access to in other ways. Also, as Lyle (2003, p. 861) pointed out, 'The value is enhanced 
when there is immediacy of recall, consonance between questions and cognitive organisation, and indirect means of introspection in complex interactive contexts, such as the classroom'.

There are also some problems associated with the use of head-mounted cameras and stimulated recall. At one level, as Houge's (2010) riversurfing study showed, the use of the head-mounted cameras can be logistically challenging. For example, their use in a natural environment, the absence of available power sources, the necessity of waterproof camera recording devices in some research contexts and possible time and resource constraints could prove problematic. Cameras that are not properly attached or regularly adjusted and monitored could potentially come loose and interfere with participants' current activity. As a result, malfunctions could interfere with data collection, particularly if researchers are not familiar with the equipment and comfortable using it correctly and efficiently. In addition, some participants may experience physical discomfort from wearing a headband and/or having the weight of the camera on their head. Brown et al. (2008), in their study of mountain bikers and recreational walkers, found that mountain bikers who routinely wore helmets were more comfortable wearing the equipment than walkers who wore it on a headband. They also found that the location of the activity could make participants feel strange, or out of place, for example while wearing the equipment in an urban park, as opposed to wearing it in more remote locations with less chance of meeting other people. Therefore, it is important to ensure the smooth operation of the equipment, so that its impact on the participants is as unobtrusive as possible. This will help participants become less aware of, or forget about the equipment and there will be less danger of a social desirability bias being introduced into the research (even prior to the interviews), by participants 'performing' for the camera (Dempsey 2010). Also, depending on the activity, there may also be a risk of damaging the expensive equipment during filming if collisions with rocks, trees or the ground are a possibility.

At a different level, simple head-mounted cameras cannot provide researchers with information about the nature of the participant's vision during the activity. The view from the camera (viewed later during the interviews) gives no information about whether the participant is gazing, glancing or scanning, staring vacantly or using peripheral vision (Brown et al. 2008). However, more sophisticated, but much more expensive gaze-aligned head-mounted cameras are now available and have been used in medical and other work (e.g. Schneider et al. 2007). Finally, Lyle (2003) warned that there is a possibility that stimulated recall may cause some participants to change or reorder their accounts when their deeper memory structures are activated by viewing the video footage. This might occur as a means of maintaining biases of control in the research process, or for a priori affirmation of theory. This additional disadvantage to stimulated recall could pose a serious threat to the accuracy of interview statements in qualitative research and researchers need to be alert to the possibility of it occurring with some participants. The whole problem of obtaining the truth in qualitative interviews was a subject for discussion in Randall and Phoenix's (2009) reflections on narrative interviews (see also Smith 2010). In their publication, they highlighted a number of influences which may affect the truthfulness of participants' memories of a past event. These include factors such as the time since the event, the level of literacy of the participants, the personality of participants, their gender and subsequent personal or cultural influences on their memory of events. In addition, Randall and Phoenix (2009, p. 128) 
also draw attention to aspects of the interview itself which may affect the memory and truthfulness of interviewees:

For them any prior knowledge about the aims of the interview, where and when the interview takes place, who is present, the power relations between parties and so forth - all of these shape how the storyteller's life is constructed, communicated and understood amid the interview setting.

Finally, there is always the possibility that, for whatever reason, participants may lie in interviews (Randall and Phoenix 2009, p. 130). Researchers, even in sport and exercise contexts in which interviews follow closely on from the activity at focus, need to understand the sometimes complicated relationship which exists between memory and truth in interviews.

\section{Conclusion}

The use of stimulated recall equipment in adventure settings presents a number of interesting challenges for researchers. While the use of this equipment in other sports or exercise contexts might prove equally challenging, it has the potential to be well worth it in terms of the actual pay-offs of using this method. It has already been used successfully to examine decision-making in orienteering (Omodei et al. 1998), social experience in mountain biking (Brown et al. 2008), the temporal dynamics of acrobatic activity (Hauw and Durand 2008) and psychological aspects of participation in whitewater adventure activities (Houge 2010). There are many other unexplored sport and exercise contexts which could benefit from the use of stimulated recall technology as a prompt to participants' memories in qualitative research. It would be advantageous if future research could identify the effectiveness of this method across a range of sport and exercise activities, environments and participants.

\section{Notes on contributors}

Susan Houge Mackenzie is an assistant professor of recreation at the University of Idaho where she conducts research on psychological aspects of adventure. Her research focuses on positive psychology theories and often incorporates head-mounted video cameras to study individual adventure experiences as they unfold. This line of research is grounded in the belief that engaging in outdoor, physical activity is essential to health and mental well-being, and can provide a profound sense of meaning and purpose to everyday life. The results of her research have been published in leisure and psychology journals. Susan's interest in diverse perspectives on adventure, sport, and psychological well-being stems from nine years of whitewater riverboard/hydrospeed guiding in areas of New Zealand (NZ), the USA, and Chile and her experiences as a competitive soccer player in the US, NZ, Australia, and Spain. She has applied these experiences to conduct mental skill training workshops for elite youth soccer players, and to develop risk management guidelines and consulting for: New Zealand's Ministry of Tourism, the NZ riverboarding industry, and a tour operator in the Galapagos Islands, Ecuador.

John $\mathrm{H}$. Kerr, $\mathrm{PhD}$, is an adjunct professor of sport \& exercise psychology with the School of Kinesiology at the University of British Columbia. Previously, he held university positions in the UK, The Netherlands, and Japan. His research interests include the influence of motivation, emotion, and arousal on performance, the psychological benefits resulting from participation in physical activities, team process, and performance of elite winning and losing teams, and aggression and violence in and around sport. He has published widely in Psychology and Sport and exercise psychology journals and is author, co-author, or editor of 
10 psychology books, including Rethinking aggression and violence in sport (2005); Counselling athletes: applying reversal theory (2001); Motivation and emotion in sport (1997); Understanding soccer hooliganism (1994). He is a former high-level rugby player and coach.

\section{References}

Apter, M.J., 1982. The experience of motivation: the theory of psychological reversals. London: Academic Press.

Apter, M.J., ed., 2001. Motivational styles in everyday life: a guide to reversal theory. Washington, DC: American Psychological Association.

Brown, K.M., Dilley, R., and Marshall, K., 2008. Using a head-mounted video camera to understand social worlds and experiences. Sociological research online, 13 (6), 1. Available from: www.socresonline.org.uk/13/6/1.html [Accessed 24 May 2010].

Charmaz, K., 2001. Qualitative interviewing and grounded theory analysis. In: J.F. Gubrium and J.A. Holstein, eds. The handbook of interview research: context and method. Thousand Oaks, CA: Sage, 675-694.

Creswell, J.W., Plano Clark, V.L., Gutmann, M.L., and Hanson, W.E., 2003. Advanced mixed methods research designs. In: A. Tashakkori and C. Teddlie, eds. Handbook of mixed methods in social and behavioral research. Thousand Oaks, CA: Sage, 209-240.

Csikszentmihalyi, M., 1975. Beyond boredom and anxiety. San Francisco, CA: Jossey-Bass.

Dempsey, N.P., 2008. Hook-ups and train wrecks: contextual problems parameters and coordination of jazz interactions. Symbolic interactions, 31 (1), 57-75.

Dempsey, N.P., 2010. Stimulated recall interview in ethnography. Qualitative sociology, 33, 349-367.

Dougherty, D.S., 2006. Gendered construction of power during discourse about sexual harassment: negotiating competing meetings. Sex roles, 54, 495-507.

Gratton, C. and Jones, I., 2004. Research methods for sport studies. New York: Routledge.

Hauw, D. and Durand, M., 2008. Temporal dynamics of acrobatic activity: an approach of elite athletes' specious present. Journal of sports science and medicine, 7, 8-14.

Houge, S.P. 2010. Reversal theory and flow: toward an integrated framework of optimal experiences in adventure activities. Unpublished thesis $(\mathrm{PhD})$. University of Otago, Dunedin, New Zealand.

Jackson, S.A., 1996. Toward a conceptual understanding of the flow experience in elite athletes. Research quarterly for exercise and sport, 67, 76-90.

Kerr, J.H., 1997. Motivation and emotion in sport: reversal theory. Hove: Psychology Press.

Kerr, J.H., 2001. Counseling athletes: applying reversal theory. London: Routledge.

Lyle, J., 2003. Stimulated recall: a report on its use in naturalistic research. British journal of educational research, 29, 861-879.

McLennan, J., Pavlou, O., Klein, P., and Omodei, M., 2005. Using video during training to enhance learning of emergency incident command and control skills. The Australian journal of emergency management, 20, 10-14.

Neil, R., Mellalieu, S.D., and Hanton, S., 2009. The contribution of qualitative inquiry towards understanding competitive anxiety and competition stress. Qualitative research in sport and exercise, 1, 191-205.

Omodei, M., McLennan, J., and Whitford, P., 1998. Using a head-mounted video camera and two-stage replay to enhance orienteering performance. International journal of sport psychology, 29, 115-131.

Patton, M.Q., 1990. Qualitative evaluation and research methods. Newbury Park, CA: Sage.

Randall, W. and Phoenix, C., 2009. The problem with truth in qualitative interviews: reflections from a narrative perspective. Qualitative research in sport and exercise, 1, 125-140.

Schneider, E., Schneider, E., Bartl, K., Boning, G., Dera, T., Jauch, K.W., et al., 2007. Imaging the world from a surgeon's perspective with a gaze-aligned head-mounted camera. Clinical neurophysiology, 118, 93-94.

Smith, B., 2010. Narrative inquiry: ongoing conversations and questions for sport psychology research. International review of sport psychology, 3, 87-107.

Sparkes, A. and Smith, B., 2009. Judging the quality of qualitative inquiry. Psychology of sport and exercise, 10, 491-497. 